\title{
Co-transplantation of autologous bone marrow mesenchymal stem cells and Schwann cells through cerebral spinal fluid for the treatment of patients with chronic spinal cord injury: safety and possible outcome
}

\author{
S Oraee-Yazdani ${ }^{1,2}$, M Hafizi $^{2}$, A Atashi ${ }^{2}$, F Ashrafi $^{1}$, A-S Seddighi ${ }^{1}$, SM Hashemi ${ }^{3}$, A Seddighi $^{1}$, \\ M Soleimani ${ }^{4}$ and A Zali ${ }^{1}$
}

\begin{abstract}
Study design: This is a clinical trial (phase 1).
Objectives: The objective of this study was to asses the safety and feasibility of bone marrow mesenchymal stem cell (MSC) and Schwann cell (SC) co-injection through cerebral spinal fluid (CSF) for the treatment of patients with chronic spinal cord injury.

Methods: Six subjects with complete spinal cord injury due to trauma according to International Standard of Neurological Classification for Spinal Cord Injury (ISNCSCI) developed by the American Spinal Injury Association were enrolled. They received autologous co-transplantation of MSC and SC through lumbar puncture. Neurological status of the patients was determined by ISNCSCI, as well as by assessment of functional status by Spinal Cord Independent Measure. Before and after cell transplantation, magnetic resonance imaging (MRI) was performed for all the patients. Before the procedure, all the patients underwent electromyography, urodynamic study (UDS) and MRI tractograghy. After transplantation, these assessments were performed in special cases when the patients reported any changes in motor function or any changes in urinary sensation.

Results: Over the mean 30 months of follow-up, the radiological findings were unchanged without any evidence of neoplastic tissue overgrowth. American Spinal Injury Association class in one patient was changed from A to B, in addition to the improvement in indexes of UDS, especially bladder compliance, which was congruous with axonal regeneration detected in MRI tractography. No motor score improvement was observed among the patients.
\end{abstract}

Conclusion: No adverse findings were detected at a mean of 30 months after autologous transplantation of the combination of MSCs and SCs through CSF. It may suggest the safety of this combination of cells for spinal cord regeneration.

Spinal Cord (2016) 54, 102-109; doi:10.1038/sc.2015.142; published online 3 November 2015

\section{INTRODUCTION}

Therapeutic cell transplantation has become a promising concern that has raised much hope in the regeneration of central nervous system injuries. This is most important when it becomes clear that the ability of the injured spinal cord to regenerate itself is limited. ${ }^{1}$

The ability of mesenchymal stem cells (MSCs) to differentiate into a variety of cells, feasibility of isolation, production of neuroprotective and immunomodulatory cytokines and preparation of a permissive environment for axonal growth result in the conclusion that these cells are an attractive source for cell therapy. ${ }^{2}$ Schwann cells (SCs), which derive from the neural crest cells, can express and secrete various growth factors, thereby creating a permissive environment for axonal regeneration. In addition, through the production of the myelin sheath, SCs can facilitate the progress of electrical transmission along the axons. ${ }^{3}$ Many clinical trials on the application of these cells for traumatic spinal cord injuries have been completed or are now ongoing, although the range of the results are widely different and also the efficiency is controversial. ${ }^{4}$

In our previous study, we assessed the safety and possible outcome of autologous SC and bone marrow MSC co-transplantation for the treatment of patients with chronic spinal cord injury through direct transplantation of this combination into the injured area. ${ }^{5}$

In many studies, the cells have been injected into the lesion directly through a needle. In addition to the procedure, this approach is potentially harmful to the parenchyma; direct injection into the spine lesion with a needle is clinically unrealistic because the lesion is widely spread or multifocal. ${ }^{6}$ It has been shown that transplanted cells delivered by lumbar puncture into the CSF may home better into

${ }^{1}$ Functional Neurosurgery Research Center, Shahid Beheshti University of Medical Sciences, Tehran, Iran; ${ }^{2}$ Department of Stem Cell Biology, Stem Cell Technology Research Center, Tehran, Iran; ${ }^{3}$ Department of Immunology, School of Medicine, Shahid Beheshti University of Medical Sciences, Tehran, Iran and ${ }^{4}$ Department of Hematology, Faculty of Medical Sciences, Tarbiat Modares University, Tehran, Iran

Correspondence: Dr A-R Zali or Dr A Seddighi, Functional Neurosurgery Research Center, Shahid Beheshti University of Medical Sciences, PO box: 1989934148, Tehran, Iran. E-mail: dr_alirezazali@yahoo.com or afsounseddighi@gmail.com

or Dr M Soleimani, Department of Hematology, Faculty of Medical Sciences, Tarbiat Modares University, P0 box: 1997775555, Tehran, Iran.

E-mail: soleim_m@modares.ac.ir

Received 8 November 2014; revised 22 May 2015; accepted 15 June 2015; published online 3 November 2015 
the injured tissue, especially if they are delivered away from the hostile environment of acute injury, and thus they have a greater opportunity to survive, migrate and differentiate in the injury site. , $7,8^{-1}$

In this study, we assessed the safety and possible outcomes of co-transplantation of autologous SCs and MSCs through lumbar intrathecal injection in patients suffering from chronic traumatic spinal cord injury.

\section{PATIENTS AND METHODS}

\section{Study design}

Six patients (four men and two women) with a mean age of 33.3 years (range, $22-45$ years) were enrolled in this study. The mean time between the injury and transplantation was $38.1 \pm 15.28$ months. All patients had complete (American Spinal Injury Association Impairment Scale (AIS) grade A), cervical (one case) or thoracic (five cases) lesions. Road traffic accidents in half of the patients and fall from a height in the other half were responsible for these lesions. Demographic and clinical features of the patients are summarized in Table 1.

Inclusion criteria consisted of chronic spinal cord injury (SCI) with at least a 1-year gap after injury; the absence of additional serious medical complications, brain disease or psychological disturbance; the absence of lower motor neuron disease on electromyography (EMG) and nerve conduction velocity (NCV); no compression, stenosis or tethering in the magnetic resonance images of the spinal cord taken in the beginning of the study; successful decompression or stabilization of SCI at least $>1$ year before transplantation; and demonstration of complete spinal cord injury and stable condition of sensory, motor and functional status. Patients who presented with any of the aforementioned criteria were excluded from the study. One of the patients (C7 injury) had been treated with corpectomy and anterior fixation, and the others underwent posterior spinal fixation with instrumentation.

After Injury and before enrolling in the study, the patients had gone through the normal comprehensive management of spinal cord injury, including rehabilitation programs with different degrees individually. At least six months before surgery and by the end of the study, a complete regular rehabilitation program including physical therapy was considered for all patients.

The International Standard of Neurological Classification for Spinal Cord Injury (ISNCSCI) scoring system (motor and sensory), developed by the American Spinal Injury association, was used to determine the preoperative and postoperative neurological status, and the third version of Spinal Cord Independent Measure (SCIM) was used to assess the functional status of the patients. ${ }^{9}$

All patients were independently examined by two trained expert clinicians, before surgery and every 6 months after transplantation, and the scores were recorded during each examination. To examine any changes in the spinal cord and surrounding tissues, MR images were taken before enrollment and at 6,12 , 18 and 24 months after transplantation.

Preoperatively, for all the patients, EMG-NCV, urodynamic study (UDS) and magnetic resonance imaging tractography were performed. To differentiate voluntary muscle contraction from reflex or involuntary spontaneous limb movement, EMG-NCV was performed postoperatively in special cases when the patients reported any changes in motor function. Similarly, UDS was

Table 1 Demographic and clinical features of the patients

\begin{tabular}{cccccccc}
\hline Patient & Sex & Age (year) & $\begin{array}{c}\text { Time from } \\
\text { SCl } \\
\text { (month) }\end{array}$ & $\begin{array}{c}\text { ASIA } \\
\text { (mevel } \\
\text { of } \\
\text { injury }\end{array}$ & $\begin{array}{c}\text { Zone of Partial } \\
\text { Preservation }\end{array}$ & $\begin{array}{c}\text { Follow- } \\
\text { up } \\
\text { (month) }\end{array}$ \\
\hline 1 & F & 28 & 36 & A & T4 & T5 & 36 \\
2 & M & 45 & 22 & A & T2 & T2 & 25 \\
3 & M & 32 & 62 & A & T5 & T5 & 28 \\
4 & F & 31 & 51 & A & T11 & T12 & 36 \\
5 & M & 22 & 30 & A & T10 & T10 & 27 \\
6 & M & 42 & 28 & A & C7 & C7 & 32 \\
\hline
\end{tabular}

Abbreviations: ASIA, American Spinal Injury Association; F, female; M, male; SCl, spinal cord injury. performed when the patients reported any changes in bladder function or urinary sensation. Magnetic resonance imaging tractography was only performed for the patients who showed significant improvement in their neurological examination to further clarify the improvement. The mean follow-up period was $30.6 \pm 4.7$ months.

This study was designed in accordance with the Declaration of Helsinki Principles and was approved by the Ethics in Medical Research Committee of the Shahid Beheshti University of Medical Sciences and Stem Cell Technology Research Center. We certify that all applicable institutional and governmental regulations concerning the ethical use of human volunteers were followed during the course of this research.

\section{Cell isolation and transplantation}

Collection of autologous SCs and MSCs was performed after hospitalization of the patients in the operation room under sterile conditions. The patients were discharged after the procedure on the next day.

The SCs were collected from the sural nerve according to the protocol that we used in our previous study. ${ }^{5}$ Briefly, the sural nerve of the patient that was collected from the calf region was sliced into 1- to 2- $\mathrm{mm}$ pieces and treated with collagenase (1.4 $\mathrm{U} \mathrm{ml}^{-1}$; Sigma, St. Louis, MO, USA) and Dispase (2.4 $\mathrm{U} \mathrm{ml}^{-1}$; Sigma). At first, the cells were incubated in DMEM/F12, not including fetal bovine serum (FBS, Gibco), for 5 days. A gradual increase in the concentration of FBS in culture up to $10 \%$ was performed during a period of 1 week. The isolated cells were determined with S100 immunocytological staining and double checked with P75 immunocytological staining using the same protocol used in our previous study. ${ }^{5}$

Bone marrow blood $(100 \mathrm{ml})$ was aspirated from the iliac bone for collection of bone marrow stem cells according to the protocol that we used in our previous study. ${ }^{5}$ In brief, the samples went through a density gradient by Ficoll $\left(1.077 \mathrm{~g}^{-1}\right.$, Sigma) at a ratio of 1:3. After centrifugation, the mononuclear cell layer was recovered from the gradient interface. To isolate mononuclear cells, the cells were centrifuged three times with less gradient and time to separate platelets. We assessed the ability of isolated cells to differentiate to adipogenic and osteogenic cells in addition to analyzing the cell surface markers. ${ }^{5}$

The MSCs and SCs were cultured separately, and before transplantation a mixture of isolated cells composed of MSCs at a final concentration of $1 \times 10^{6}$ cells per $\mathrm{ml}$ and SCs at a final concentration of $1 \times 10^{6}$ cells per $\mathrm{ml}$ (total volume of $2 \mathrm{ml}$ ) was prepared and transplanted into the L4/L5 level through lumbar puncture.

After cell preparation, the patients were hospitalized again (approximately 2 weeks after biopsy procedure), and cell transplantation was performed in the operation room under sterile conditions. After aseptic preparation of the injection site, lumbar puncture was performed in the lateral position through the L4/5 space using spinal needle $24 \mathrm{G}$. After confirmation of entrance to the subarachnoid space by CSF existing through the spinal needle, a mixture of cells in a total volume of $2 \mathrm{ml}$ was slowly injected. The needle was kept in place for $1 \mathrm{~min}$ to prevent leakage.

\section{RESULTS}

The collected cells had similar characteristics with the cells that we used in previous study, and thus SCs were positive for S100 and P75 and bone marrow MSCs could differentiate into adipogenic and osteogenic cells and were positive for CD73, CD90 and CD105 and negative for CD45 in cell surface markers analysis (data not shown). ${ }^{5}$ Similarly, no contamination in cell culture and no abnormality in Cytogenetic analysis (karyotype) was seen (data not shown).

No systemic complications due to transplanted cells such as fever, hypersensitivities, anaphylactic shock, rush or inflammation in the site of injury was observed. No meningitis or any infectious complications related to the transplant procedure was detected.

Because of previous spinal instrumentation, some of the worst effects on visibility of images in all the patients were seen. Nevertheless, the radiological findings were unchanged, and no magnetic resonance imaging evidence of neoplastic tissue overgrowth was detected (Figure 1). 

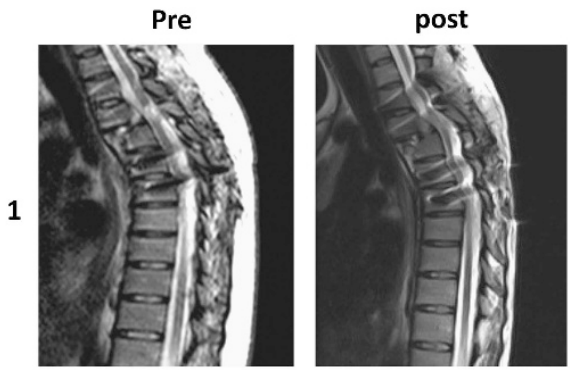

2
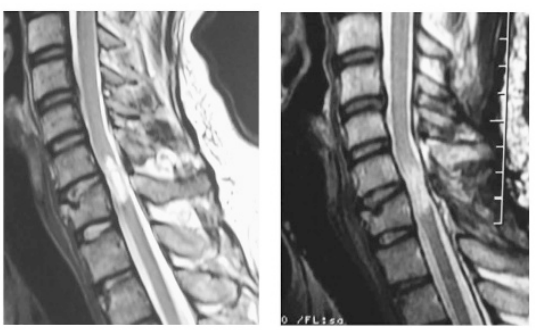

3
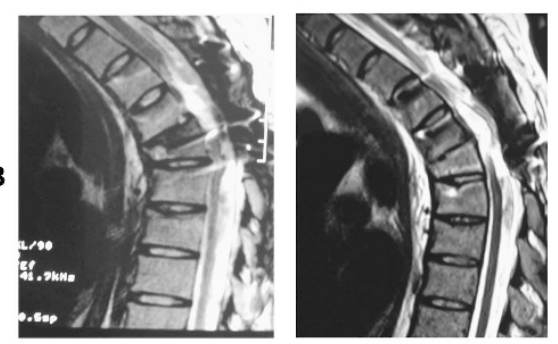

4
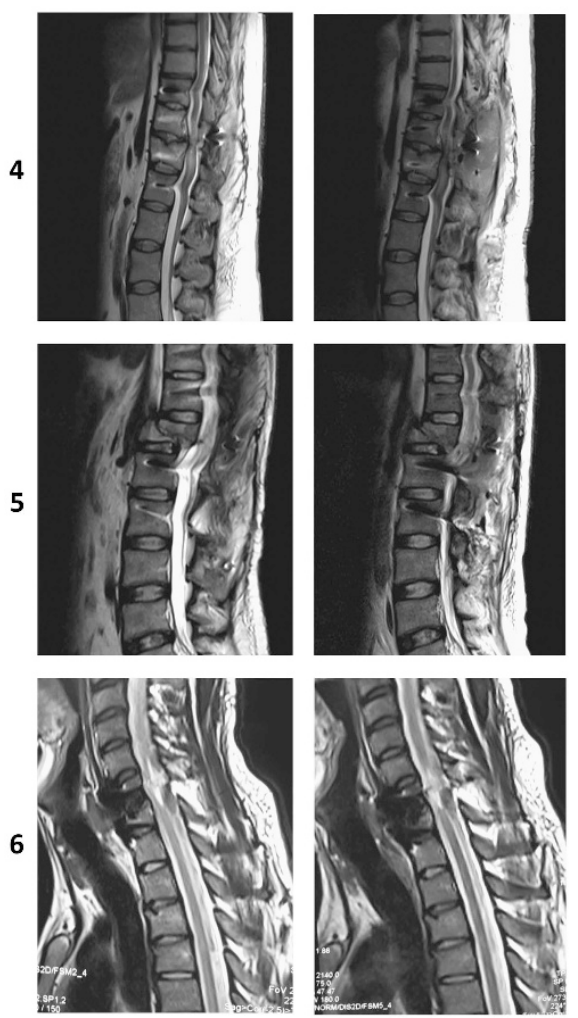

Figure 1 Magnetic resonance images of all the patients (1-6) before and after cell transplantation. No evidence of neoplastic tissue overgrowth, syringomyelia or pseudomeningocele was seen.
All six patients had undergone regular rehabilitation program at 6 months before transplantation and evaluated at the beginning of the rehabilitation program at the time of transplantation and also re-evaluated 6,12, 18 and 24 months after surgery by means of the ISNCSCI and SCIM scoring system.

After 6 months of rehabilitation, no improvement was seen in ISNCSCI and SCIM. In the examination before transplantation, patient 1 had a sensory level at T5, the pinprick and light-touch ISNCSCI scores were 48 and no sensation at the perianal region was detected. Motor score according to the ISNCSCI scoring system was fifty. The patient was categorized in AIS grade A, complete lesion (No motor or sensory function below the injury site or in the sacral segments S4-S5).

She had significant improvement in ISNCSCI sensory scores in the course of the study. Approximately 4 months after injection, improvements at the sensory level were detected, and 1 year after transplantation the patient had perianal sensation, although it was hypoestethic. According to ISNCSCI, pinprick and light-touch scores were 79 with perianal sensation. No motor improvement was seen in the period of the study. Thus, the patient classification in AIS grade was changed from A to B with incomplete lesions (that is, sensory but not motor function is preserved below the neurological level, which includes the sacral segments S4-S5). No change in SCIM score was seen.

EMG-NCV before transplantation showed upper motor neuron disease and no anal sphincter function. Similarly, UDS revealed detrusor muscle hyperactivity, no urinary sensation and poor bladder compliance.

Approximately 3 years after transplantation, EMG-NCV revealed minimal voluntary motor unit action potential in the anal sphincter (data not shown). At the same time, UDS showed bladder filling sensation, good compliance and capacity with a very mild detrusor overactivity; all of them indicate acceptable storage phase (Figure 2). Magnetic resonance tractography is a three-dimensional modeling technique that is used to visually represent neural tracts using data collected by diffusion tensor imaging. In accordance with a significant change in the neurological examination and paraclinic studies, this specific imaging was performed for patient 1 . Imaging revealed axonal regeneration in the injured area, 36 months after transplantation (Figure 3).

Patient 2 had improvement in ISNCSCI sensory score, and thus before transplantation the patient had sensory level at T2, the pinprick and light-touch scores were 36 and no sensation at the perianal region was detected. After over 25 months of follow-up, pinprick and lighttouch scores were 51 and no perianal sensation was detected. In other words, sensory level was improved for three levels. Similar to other patients, no motor improvement was seen in the course of the study. This patient reported some urinary sensation 1 year after transplantation, but UDS revealed no change in comparison with preoperative UDS (data not shown). Despite improvement in sensory scores, no progress was observed in the AIS grade of the patient.

In the remaining patients, no progress in sensory or motor scores, as well as AIS grade, was seen. Changes in sensory or motor scores in patients according to ISNCSCI are summarized in Table 2. On the basis of the SCIM sale, no change in scores was documented among the patients (data not shown).

During the course of the study, the patients reported widely subjective changes: favorable experiences such as enhanced stability and trunk equilibrium in the sitting position, urinary sensation and feeling of defecation, and unfavorable experiences such as an increase 

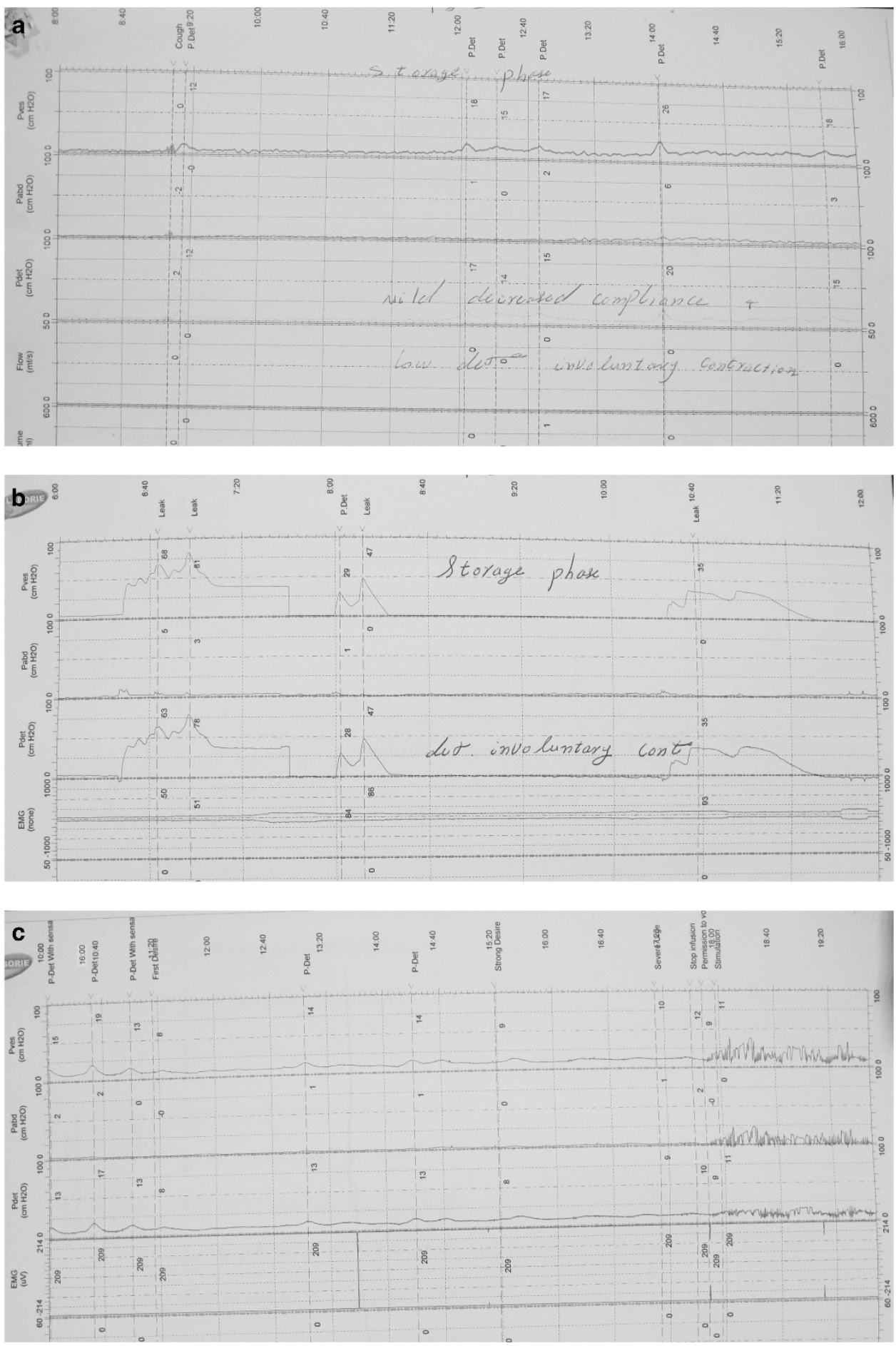

Figure 2 Urodynamic study related to patient 1. (a) At the time of injury (2007) three years before transplantation, the patient had no bladder filling sensation and mild detrusor overactivity. (b) At the time of transplantation (2010), the patient still had no bladder filling sensation in addition to severe detrusor overactivity and poor bladder compliance. (c) Three years after cell transplantation (2013), the patient's first sensation for urination occured when the bladder volume was $146 \mathrm{cc}$. Detrusor overactivity decreased and bladder compliance was improved.

in neuropathic pain, paresthesia and lower-extremity muscle spasm (Table 3).

Improvement of equilibrium in the sitting position was expressed by four of the six patients in the course of the study. Before transplantation, all the patients had no sphincter control or urination and defecation sensation. At the end of the study, urinary sensation and feeling of defecation was expressed by patients 1, 2, 5 and 6 who reported urinary sensation alone (Table 3 ). In the spite of this, the favorable personal reports were not enough to change the scores, according to SCIM (data not shown). Except in patient 1, UDS and EMG-NCV revealed no change in the other patients (data not shown). None of the patients achieved sphincter control. 

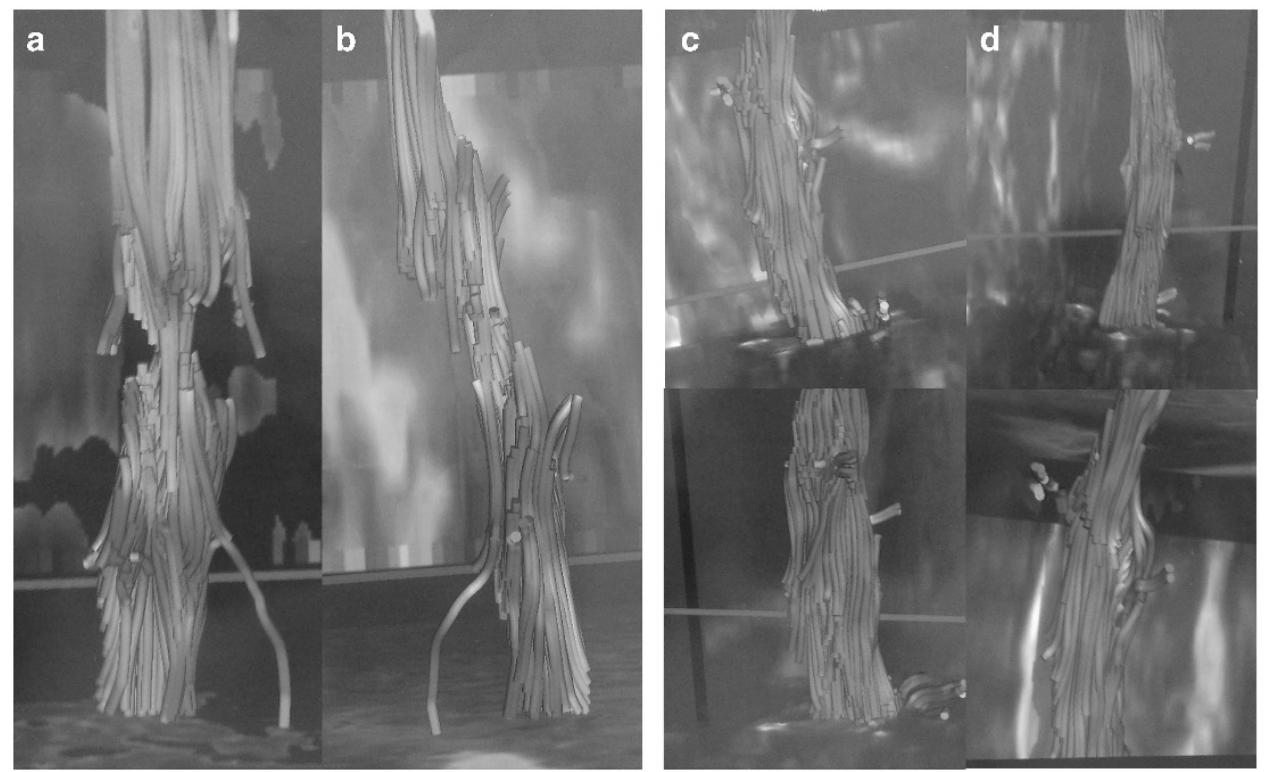

Figure $3 \mathrm{MRI}$ tractography related to patient 1 , before (a, b) and 36 months after cell transplantation (c, d). Images revealed axonal regeneration after cell treatment. A full color version of this figure is available at the Spinal Cord journal online.

Table 2 Motor (M) and sensory (S) scores according to International Standard of Neurological Classification for Spinal Cord Injury, from 6 months before to 24 months after transplantation (every 6 months)

\begin{tabular}{|c|c|c|c|c|c|c|c|c|c|c|c|c|}
\hline \multirow[t]{2}{*}{ Patients } & \multicolumn{2}{|c|}{$\begin{array}{l}6 \text { Months before } \\
\text { transplantation }\end{array}$} & \multicolumn{2}{|c|}{$\begin{array}{l}\text { At the time of } \\
\text { transplantation }\end{array}$} & \multicolumn{2}{|c|}{$\begin{array}{l}6 \text { Months after } \\
\text { transplantation }\end{array}$} & \multicolumn{2}{|c|}{$\begin{array}{l}12 \text { Months after } \\
\text { transplantation }\end{array}$} & \multicolumn{2}{|c|}{$\begin{array}{l}18 \text { Months after } \\
\text { transplantation }\end{array}$} & \multicolumn{2}{|c|}{$\begin{array}{l}24 \text { Months after } \\
\text { transplantation }\end{array}$} \\
\hline & $S$ & $M$ & $S$ & $M$ & $S$ & $M$ & $S$ & $M$ & $S$ & $M$ & $S$ & $M$ \\
\hline 1 & 48 & 50 & 48 & 50 & 58 & 50 & 79 & 50 & 79 & 50 & 79 & 50 \\
\hline 2 & 36 & 50 & 36 & 50 & 38 & 50 & 51 & 50 & 51 & 50 & 51 & 50 \\
\hline 3 & 48 & 50 & 48 & 50 & 48 & 50 & 48 & 50 & 48 & 50 & 48 & 50 \\
\hline 4 & 72 & 50 & 72 & 50 & 72 & 50 & 72 & 50 & 72 & 50 & 72 & 50 \\
\hline 5 & 70 & 50 & 70 & 50 & 74 & 50 & 74 & 50 & 74 & 50 & 74 & 50 \\
\hline 6 & 24 & 25 & 24 & 25 & 24 & 25 & 24 & 25 & 24 & 25 & 24 & 25 \\
\hline
\end{tabular}

Before enrolling in the study, four of the six patients had some degree of neuropathic pain. Three of them have experienced an increase in neuropathic pain six months after transplantation, which was improved by medical treatment. Similarly, five of the six patients suffered from paresthesia before enrolling in the study. Six months after transplantation, paresthesia was significantly increased in two patients, which required medical treatment. Six months to 1 year after transplantation, three of the four patients with muscle spasm at the beginning of the study experienced an increase in their lowerextremity spasms. These spasms were relieved to some extent by antispasmotic drugs (Table 3).

\section{DISCUSSION}

Direct injection of the cells into the lesions are too invasive for the spinal cord. ${ }^{1}$ Moreover, although the locally injected stem cells can migrate in the rostral-caudal direction from the injection site, migration in the dorsoventral direction is restricted, which shows difficulty of cell delivery by local injection into the central parenchyma, ${ }^{10}$ while it appears that central parenchyma is frequently injured most severely in contusion injury. ${ }^{11}$ In addition, it has been shown that with noninvasive methods such as intravenous injection stem cells can migrate into the injured spinal cord parenchyma. ${ }^{1}$
In several studies, cell transplantation through less invasive methods such as intravenous or lumbar puncture has been examined. ${ }^{8,12-15}$ It has been shown that transplanted cells with the lumbar puncture method can migrate through the cerebrospinal fluid to the injured site, ${ }^{8,16}$ and the results of this method are superior to systemic transplantation of cells. ${ }^{15}$

Previously, SCs and MSCs have been applied in some studies, but individually and through direct injection or lumbar puncture, for which the safety appliance was identified..$^{13,17,18}$ The safety of cotransplantation of autologous SCs and bone marrow MSCs for the treatment of patients with chronic spinal cord injury through direct transplantation of this combination into the injured area has been documented in our previous study. ${ }^{5}$

In this study, a mixture of SCs and bone marrow MSCs were administered intrathecally in six patients who suffered from complete traumatic spinal cord injury. Because the study was performed as a safety phase of the clinical trial, cases were selected among patients with no improvement in neurological or functional status after spinal cord injury before enrolling in the study.

No evidence of change in radiological findings consistent with tumor overgrowth was seen in serial intervening MR imaging for a mean of three years after cell transplantation. In addition, no report of 


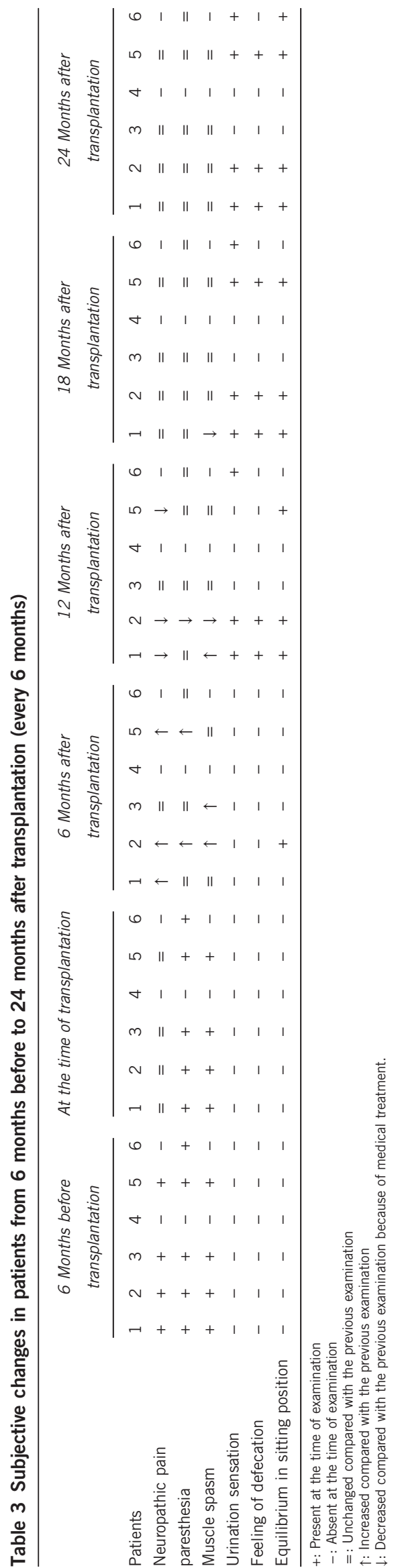

systemic complications including allergic reactions caused by cellular transplantation, as well as infectious complications, was documented. These findings suggested that this combination of cells could be safe.

In this study, we did not consider randomly assigned control subjects. Indeed, the main purpose of this study was to assess the safety and possible outcomes of the mentioned cell combination transplantation through intrathecal injection. Although it recommends that phase 1 trials include randomly assigned control subjects, it is not necessary. ${ }^{19}$ At least a 2-year history of stable neurological status before cell transplantation among the selected patients decreases the likelihood of spontaneous recovery to a very negligible degree. ${ }^{20}$

Each patient received rehabilitation programs with different degrees before enrolling in the study. With regard to our decision to provide a complete regular rehabilitation program after transplantation, we considered the same program for 6 months before transplantation to exclude dependency of any suspected improvement to the rehabilitation program. In accordance with the fact that no improvement was seen in ISNCSCI scores and SCIM scale after 6 months of rehabilitation (before transplantation), it appears that rehabilitation cannot improve sensory and motor scores by itself in patients with chronic spinal injuries. It does suggest that improvements are independent of rehabilitation programs.

Although improvement in functional status after rehabilitation programs is well documented, most of these progressions occur 1 year after rehabilitation. ${ }^{21}$ There is the same concept about eventual improvement in sensory and motor scores according to the ISNCSCI scoring system, although with less degree, in patients who suffered from complete spinal cord injury. ${ }^{21}$ It has been shown that only after 4 months the progression of improvement according to SCIM scale will reach its plateau value. ${ }^{22}$ The minimum time after injury for patients before enrolling in the study was 22 months, as demonstrated in Table 1. Indeed, the subjects were selected among patients with complete spinal cord injury and stable condition of sensory, motor and functional status. Thus, no sensible improvement in functional status with continuing rehabilitation program, will be explained by reaching the patients to plateau value.

In patient 1 , results of neurological examination and paraclinic studies suggested gradual improvement in the course of the study, including improvement in ISNCSCI scores and changing the AIS grade with regard to perianal sensation from A (complete motor and sensory) to B (complete motor and incomplete sensory). These changes were justified with EMG-NCV results, as well as with an increase in urinary sensation, which is confirmed with the results of UDS indicating progress in indexes, especially in storage phase and axonal regeneration in the injured area demonstrated in magnetic resonance imaging tractography.

Although patient 2 had considerable improvement in sensory scores, among the other patients no sensory or motor score improvement was seen. These findings are in accordance with the results of other studies in patients with chronic spinal cord injuries. ${ }^{18}$

Despite improvement in ISNCSCI scores in some of the patients, SCIM scores remained unchanged in the course of the study. This subject may contribute to the functional nature of this scale. According to SCIM, motion scores (including need for assistance in different activities) were unchanged for patients even with subjective reports of more stability and trunk equilibrium, as well as scores of sphincter management of both bladder and bowel for patients with subjective reports of urinary sensation and feeling of defecation, respectively. As mentioned above, this subject perhaps is related to severity and chronicity of the lesions, as well as the stability of the patients' condition after enrollment in the study (at least 2 years after 
injury). For example, Patients 1 and 5 required intermittent selfcatheterization with continence between cathetherization, during the study without change.

Studies have shown that the cell transplantation strategy increases the risk of neuropathic pain related to aberrant regeneration of axonal damage. ${ }^{23,24}$ In our study, neuropathic pain and muscle spasm increased in $50 \%$ of the patients, which is more than what has been observed in our study and other previous studies. ${ }^{5,18}$ In accordance with a small number of patients and lack of a control group, we could not say with confidence that intrathecal administration of this mixture of cells may increase the risk of neuropathic pain or muscle spasm development. Studies with larger volume sizes and control group consideration in phase II are required for definitive comment on this subject.

In our previous study, we assessed safety and possible outcomes of direct injection of the same combination of cells for the treatment of chronic spinal cord injury in patients with demographic properties and neurological deficits, such as the patients in the present study (Complete SCI class A).

With intrathecal injection of this combination of cells with the same direct delivery method, no adverse radiological findings or systemic complications were seen, although some surgical complications such as postoperative hematoma or pain after surgery were eliminated with this present method compared with our previous study. In addition, duration of hospitalization was reduced considerably with intrathecal injection compared with the direct injection method.

In view of the improvement of patients who were enrolled in these studies, in addition to favorable subjective reports of patients, considerable improvement in sensory level was seen in two patients, and according to AIS grading one patient was upgraded from level A to level B. In the same patient, improvement in UDS indexes was demonstrated. In case of direct injection in the previous study, despite the favorable subjective reports of patients, improvement in sensory level in three patients was negligible, and no change in AIS grade was demonstrated among the patients.

Because of safety measures applied in this study, we are unable to compare the results with our previous study. But with regards to the promising results and the non-invasiveness of intrathecal injection, it could be seen as an alternative way to direct injection for cellular transplantation.

Considering the ability of MSCs to promote tissue sparing, axonal regeneration and re-myelination, these cells are attractive candidates for transplantation into human patients because they can be easily collected, expanded and banked, or derived directly from the patient allowing for autologous transplantation, obviating the need for immune suppression. ${ }^{15}$

Schwann cells could express a variety of growth factors, produce many surface molecules and secrete substrates such as laminin, fibronectin and collagen, which can enhance tissue regeneration. ${ }^{3}$ In addition, Schwann cells are capable of myelinating regenerating axons or re-myelinating demyelinated axons. ${ }^{3}$ It has been demonstrated that endogenous Schwann cells can migrate from the peripheral nervous system to contused spinal cord, which suggests that host Schwann cells may contribute to the recovery of spinal cord injury. ${ }^{25}$

We used a combination of MSCs and SCs with regard to the different capacities of these cells and the different mechanisms through which these cells make their effects. ${ }^{26}$ Transplantation of bone marrow stromal cells enhances infiltration and survival of Schwann cells to promote axonal sprouting following spinal cord injury, ${ }^{27}$ and therefore it appears that this combination is justified.
There are several limitations to this study. Consideration of a control group, although it is not necessary, could be worthwhile to assess of therapeutic effect of the cells. In addition, further large group studies are required to clarify the effects of either cells. Utilization of quality-of-life scales or psychological assessments seems to be useful in future studies.

\section{CONCLUSION}

Overall, our results suggest the safety of intrathecal MSC and SC combination therapy in damaged human spinal cord. This combination caused no adverse effects or new deficit in patients, and it appeared to be safe in long-term assessments. However, assessment of feasibility and investigation of true efficacy of this combination needs randomized controlled trials with larger volume sizes in phase II.

\section{DATA ARCHIVING}

There were no data to deposit.

\section{CONFLICT OF INTEREST}

The authors declare no conflict of interest.

\section{ACKNOWLEDGEMENTS}

We are grateful to Lida Langroudi from Department of Cell and Systems Biology at University of Toronto for final edition and Mahsa Babaee from Functional Neurosurgery Research Center for helping with manuscript preparation.

1 Fujiwara Y, Tanaka N, Ishida O, Fujimoto Y, Murakami T, Kajihara H et al. Intravenously injected neural progenitor cells of transgenic rats can migrate to the injured spinal cord and differentiate into neurons, astrocytes and oligodendrocytes. Neurosci Lett 2004; 366: 287-291.

2 Neirinckx V, Cantinieaux D, Coste C, Rogister B, Franzen R, Wislet-Gendebien S. Spinal cord injuries - how could adult mesenchymal and neural crest stem cells take up the challenge? Stem Cells 2013; 32: 829-843.

3 Oudega M, Xu X-M. Schwann cell transplantation for repair of the adult spinal cord. J Neurotrauma 2006; 23: 453-467.

4 Tator $\mathrm{CH}$. Review of treatment trials in humanspinal cord injury: Issues, difficulties, and recommendations. Neurosurgery 2006; 59: 957-987.

5 Yazdani So, Hafizi M, Zali A-R, Atashi A, Ashrafi F, Seddighi A-S et al. Safety and possible outcome assessment of autologous Schwann cell and bone marrow mesenchymal stromal cell co-transplantation for treatment of patients with chronic spinal cord injury. Cytotherapy 2013; 15: 782-791.

6 Satake K, Lou J, Lenke LG. Migration of mesenchymal stem cells through cerebrospinal fluid into injured spinal cord tissue. Spine 2004; 29: 1971-1979.

7 Bakshi A, Barshinger AL, Swanger SA, Madhvani V, Shumsky JS, Neuhuber B et al. Lumbar puncture delivery of bone marrow stromal cells in spinal cord contusion: a novel method for minimally invasive cell transplantation. J Neurotrauma 2006; 23: 55-65.

8 Callera F, de Melo CM. Magnetic resonance tracking of magnetically labeled autologous bone marrow $\mathrm{CD} 34+$ cells transplanted into the spinal cord via lumbar puncture technique in patients with chronic spinal cord injury: CD34+ cells' migration into the injured site. Stem Cells Dev 2007; 16: 461-466.

9 Catz A, Itzkovich M, Tesio L, Biering-Sorensen F, Weeks C, Laramee M et al. A multicenter international study on the Spinal Cord Independence Measure, version III: Rasch psychometric validation. Spinal Cord 2007; 45: 275-291.

10 Vroemen M, Aigner L, Winkler J, Weidner N. Adult neural progenitor cell grafts survive after acute spinal cord injury and integrate along axonal pathways. Eur J Neurosci 2003; 18: 743-751.

11 Ichihara K, Taguchi T, Shimada Y, Sakuramoto I, Kawano S, Kawai S. Gray matter of the bovine cervical spinal cord is mechanically more rigid and fragile than the white matter. J Neurotrauma 2001; 18: 361-367.

12 Neuhuber B, Barshinger AL, Paul C, Shumsky JS, Mitsui T, Fischer I. Stem cell delivery by lumbar puncture as a therapeutic alternative to direct injection into injured spinal cord. J Neurosurg Spine 2008; 9: 390-399.

13 Saito F, Nakatani T, Iwase M, Maeda Y, Murao Y, Suzuki Y et al. Administration of cultured autologous bone marrow stromal cells into cerebrospinal fluid in spinal injury patients: a pilot study. Restor Neurol Neurosci 2012; 30: 127-136.

14 Callera F, do Nascimento RX. Delivery of autologous bone marrow precursor cells into the spinal cord via lumbar puncture technique in patients with spinal cord injury: a preliminary safety study. Exp Hematol 2006; 34: 130-131. 
15 Paul C, Samdani AF, Betz RR, Fischer I, Neuhuber B. Grafting of human bone marrow stromal cells into spinal cord injury: a comparison of delivery methods. Spine 2009; 34 328.

16 Nishida K, Tanaka N, Nakanishi K, Kamei N, Hamasaki T, Yanada S et al. Magnetic targeting of bone marrow stromal cells into spinal cord: through cerebrospinal fluid. Neuroreport 2006; 17: 1269-1272.

17 Bhanot Y, Rao S, Ghosh D, Balaraju S, Radhika CR, Satish Kumar KV. Autologous mesenchymal stem cells in chronic spinal cord injury. Br J Neurosurg 2011; 25: 516-522.

18 Yoon S, Shim Y, Park Y, Chung J, Nam J, Kim M et al. Complete spinal cord injury treatment using autologous bone marrow cell transplantation and bone marrow stimulation with granulocyte macrophage-colony stimulating factor: Phase I/II clinical trial. Stem Cells 2007; 25: 2066-2073.

19 Lammertse D, Tuszynski M, Steeves J, Curt A, Fawcett J, Rask C et al. Guidelines for the conduct of clinical trials for spinal cord injury as developed by the ICCP panel: clinical trial design. Spinal Cord 2006; 45: 232-242.

20 Fawcett J, Curt A, Steeves J, Coleman W, Tuszynski M, Lammertse D et al. Guidelines for the conduct of clinical trials for spinal cord injury as developed by the ICCP panel: spontaneous recovery after spinal cord injury and statistical power needed for therapeutic clinical trials. Spinal Cord 2006; 45: 190-205.
21 Wirth B, van Hedel HJ, Kometer B, Dietz V, Curt A. Changes in activity after a complete spinal cord injury as measured by the Spinal Cord Independence Measure II (SCIM II). Neurorehabil Neural Repair 2008; 22: 145-153.

$22 \mathrm{Kim}$ HS, Jeong HJ, Kim MO. Changes of functional outcomes according to the degree of completeness of spinal cord injury. Ann Rehabil Med 2014; 38: 335-341.

23 Kishk NA, Gabr H, Hamdy S, Afifi L, Abokresha N, Mahmoud H et al. Case control series of intrathecal autologous bone marrow mesenchymal stem cell therapy for chronic spinal cord injury. Neurorehabil Neural Repair 2010; 24: 702-708.

24 Macias MY, Syring MB, Pizzi MA, Crowe MJ, Alexanian AR, Kurpad SN. Pain with no gain: allodynia following neural stem cell transplantation in spinal cord injury. Exp Neurol 2006; 201: 335-348.

25 Sx Z, Huang F, Gates M, Holmberg EG. Role of endogenous Schwann cells in tissue repair after spinal cord injury. Neural Regen Res 2013; 8: 177.

26 Bunge MB. Novel combination strategies to repair the injured mammalian spinal cord. J Spinal Cord Med 2008; 31: 262-269.

27 Ding P, Yang Z, Wang W, Wang J, Xue L. Transplantation of bone marrow stromal cells enhances infiltration and survival of CNP and Schwann cells to promote axonal sprouting following complete transection of spinal cord in adult rats. Am J Trans/ Res 2014; 6: 224-235. 